\title{
Colonoscopy without sedation: Patient factors alone are less likely to influence its uptake
}

Authors

Institutions
Nusrat Iqbal', Sean Ramcharan', Samer Doughan², Irshad Shaikh ${ }^{3}$

${ }^{1}$ Department of Surgery, Warwick Hospital, Warwick, UK

${ }^{2}$ Department of General Surgery, Queen Elizabeth the Queen Mother Hospital, Margate, UK

${ }^{3}$ Department of General Surgery, Norfolk and Norwich University Hospitals NHS Trust, UK submitted

2. December 2014

accepted after revision

8. February 2016

\section{Bibliography}

DOI http://dx.doi.org/

10.1055/s-0042-102877

Published online: 3.5.2016

Endoscopy International Open

2016; 04: E534-E537

(C) Georg Thieme Verlag KG

Stuttgart · New York

E-ISSN 2196-9736

\section{Corresponding author}

\section{Nusrat lqbal}

Department of Surgery

Warwick Hospital

Lakin Road

Warwick, UK CV34 5BW

Phone: +01926-495321

Fax: +01926-482603

niqbal@doctors.org.uk
Background and study aims: Conscious sedation during colonoscopy minimizes discomfort, improves polyp detection rates, and reduces technical failure, but carries medication-related risks and requires dedicated and costly recovery services. Sedation-free procedures may offer a safer alternative. We aimed to compare this group with those receiving sedation to determine differences in patient characteristics, cecal intubation rates, polyp detection rates, discomfort levels and safety in patients for whom anesthesia is high risk.

Patients and methods: Prospectively collected data from all colonoscopies performed over a 1year period at three district general hospitals were analyzed. Conscious sedation was offered to all patients and outcomes in those who refused were compared with outcomes in those who received sedation.

Results: One hundred ninety-four of 1694 (11\%) colonoscopies were performed without sedation

Meeting presentation: Pilot data presented as a poster: "Colonoscopy without sedation: is it feasible?" at European Colorectal Congress, St. Gallen,

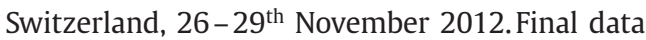
given as an oral short paper presentation: "Sedationless colonoscopy: Is there any difference in polyp detection and caecal intubation?" at the International Surgical Congress of the Association of Surgeons of Great Britain and Ireland (ASGBI), Glasgow UK on $1^{\text {st }} 3^{\text {rd }}$ May 2013.

\section{Introduction}

$\nabla$

Colonoscopy is the most common investigation for colonic pathology. In the UK it has become more frequent since the introduction of national bowel cancer screening programs, with 36,460 procedures performed in the first 3 years after their establishment [1]. To maximize efficacy in both screening and non-screening cases, it must
(61\% male, $P<0.001$ ) but rates varied between hospitals. Of these, 55\% were American Society of Anesthesiologists (ASA) grade 3 or more and 5 $\%$ experienced moderate discomfort, compared to $40 \%(P<0.0001)$ and $10 \%(P=0.023)$ respectively of those receiving sedation. They were more likely to have indications of rectal bleeding or frequency of stool and less likely to have anaemia or macroscopic inflammation at colonoscopy. Complications, completion. and polyp detection rates were similar in both groups.

Conclusions: Colonoscopy without sedation can be completed successfully in select patients without compromising comfort or polyp detection rates and is safe in those for whom anesthesia is high risk. It is therefore a safe alternative for clinicians concerned about sedation, but the findings suggest that hospital, rather than patient factors, may prevent its uptake.

be performed accurately and under conditions acceptable to the patient.

Sedation traditionally has been used to minimize technical difficulties [2] and studies demonstrate improved cecal intubation rates with it [3] and reduced patient anxiety about subsequent colonoscopy [4]. Sedation is not without risk as fewer than $1 \%$ of patients experience cardiovascular problems and respiratory distress is seen in up to 8 of every 1000 patients undergoing the procedure [5]. Sedation also places social and functional demands upon patients and, depending on the hospital's protocol, may require dedicated recovery time and an escort on discharge [6]. A study of screening colonoscopy at a university center reported a median of 20 minutes for the procedure and 21 hours for preparation, travel, and recovery [7]. Recently, sedation was found to have no effect on polyp or adenoma detection rate [3] while sedation-less procedures may reduce the cecal intubation rate [8], most likely from the 
discomfort associated with air insufflation [9]. However, pain may not be a limiting factor for intubation rates as Petrini et al. showed that of the patients offered sedation on demand, $81 \%$ underwent complete procedures without a sedative [10].

The aim of this study is to compare the level of discomfort in patients who underwent non-sedated colonoscopies (NSC) to those with sedation (SC), and to determine the effect on polyp detection and cecal intubation rates. We also assessed the effects of anaesthetic risk, indications, endoscopists, and pathology on outcomes.

\section{Patients and methods}

$\nabla$

The prospectively accrued database (Unisoft ${ }^{\circledR}$ ) of all colonoscopies performed at three district general hospitals in the UK between July 2011 and July 2012 was retrospectively analyzed. Sedation was routinely offered to all patients, however, 194 declined all medication. Throughout the procedure, patient comfort scores were obtained by two independent nurses using modified Glasgow comfort score descriptors, as outlined by the NHS Bowel Cancer Screening Programme (England, UK) [11] ( Table 1). Staff at the three units are certified by the Joint Advisory Group on GI Endoscopy (JAG, UK). They performed colonoscopies in accordance with JAG's guidelines for bowel preparation, peri-procedure care, and recovery. Anaesthetic risk was assessed using the American Society of Anesthesiologists physical status classification system (ASA grade, Table2). Details of age, sex, ASA grade, comfort scores, complications, cecal intubation rate and polyp detection rates were obtained. An adjusted cecal intubation rate was calculated by including patient discomfort and excluding poor bowel preparation and instrument inadequacy. Statistical analysis was performed using Chi-squared test, Student's t-test or Mann-Whitney, univariate analysis for odds ratios and a $P$ value less than 0.05 was considered significant.

Table 1 Modified Glasgow Comfort Score descriptors

\begin{tabular}{|ll|}
\hline Descriptor & Definition \\
\hline No & No discomfort, resting comfortably throughout \\
\hline Minimal & One or two episodes of mild discomfort, well tolerated \\
\hline Mild & $\begin{array}{l}\text { More than two episodes of discomfort, adequately } \\
\text { tolerated }\end{array}$ \\
\hline Moderate & $\begin{array}{l}\text { Significant discomfort, experienced several times } \\
\text { throughout the procedure }\end{array}$ \\
\hline & $\begin{array}{l}\text { Extreme discomfort, experienced frequently during the } \\
\text { Severe }\end{array}$ \\
\hline
\end{tabular}

Table 2 American Society of Anesthesiologists physical status classification system (ASA grade)

\begin{tabular}{|ll|}
\hline Classification & Definition \\
\hline ASA I & A normal healthy patient \\
\hline ASA II & A patient with mild systemic disease \\
\hline ASA III & A patient with severe systemic disease \\
\hline ASA IV & $\begin{array}{l}\text { A patient with severe systemic disease that is a constant } \\
\text { threat to life }\end{array}$ \\
\hline ASA V & $\begin{array}{l}\text { A moribund patient who is not expected to survive } \\
\text { without the operation }\end{array}$ \\
\hline
\end{tabular}

\section{Results}

\section{$\nabla$}

A total of 1694 colonoscopies were performed over a year, of which 194 were without sedation (11\%). Table 3 summarizes the key findings for both SC and NSC patients. In both groups colonoscopies were completed within similar time frames $(P=$ 0.590 ). There was a male predominance in the NSC group (male to female ratio $1.6: 1)$, which was not demonstrated in the SC group $(1: 1.2 P<0.001)$. There was no gender difference in discomfort levels $(P=0.102)$. A single endoscopy unit carried out more colonoscopies without sedation than others within the organization (Hospital A, $P<0.0001$ ). However, after excluding those who performed less than 100 cases (none of whom carried out NSCs), there were no differences in the numbers or rates of incomplete colonoscopies performed by the 10 high-volume endoscopists $(P=0.105)$. A greater proportion of patients were referred for bleeding $(P=0.034)$ or frequency of stool $(P=0.036)$, while fewer were likely to have anaemia $(P=0.014)$. All ASA grades were represented in both groups but there were more grade 3 patients in the NSC group $(P=0.0003)$. A greater proportion experienced lower levels of discomfort (no discomfort $43 \%$, minimal 29\%, 13\% mild discomfort, $P<0.001$ ). Macroscopic inflammation was associated with more moderate and severe discomfort across both groups. There were a comparable number of complications; three cases of mechanical damage to scope and two cases of haemorrhage occurred in the sedated group. There were no sedation-related complications noted. After multivariate analysis, a higher ASA grade correlated to NSC (p,0.001).

Polyps were found in 51 out of 194 NSC patients (26\%) and comparable to the SC group ( $23 \% P=0.249$ ). The rates of failed cecal intubation were also similar at $11 \%$ and $10 \%$ respectively $(P=$ 0.624). Incomplete colonoscopies in the NSC group were due to inadequate bowel preparation, angulation or fixity of the distal sigmoid, instrument inadequacy, and, in three cases, patient discomfort; the adjusted cecal intubation rate was 95.4\% ( Table4).

\section{Discussion \\ $\nabla$}

When compared to SC, NSC offers patients a safe investigation with shorter recovery time without the assistance of an escort and with return to normal daily activities afterwards. Anecdotally, NSC facilitates better communication between the endoscopist and the patient, which may assist in positional changes towards successful completion. In our study, all patients were offered sedation at the start, and if they refused, it was offered again if these patients experienced discomfort during the procedure. From our data, we could not determine why patients did not want sedation or why some patients who started without sedation required that treatment when difficulty was encountered. Of the 194 NSC patients, there was a male predominance. While colorectal adenoma is more prevalent in men [12], polyp detection rates were similar in both SC and NSC patients. Arguably this may suggest under-detection of polyps, but that is less likely because the procedures were performed by JAG-accredited and experienced screening endoscopists. A larger study may be needed to further address this issue. In addition, we included patients referred via the suspected cancer or screening pathways, who may have a higher risk for colorectal neoplasia, but a risk adjusted analysis of these factors requires a larger study.

As the level of discomfort experienced by patients was recorded at three sites within a single organization, interobserver varia- 


\begin{tabular}{|c|c|c|c|c|c|}
\hline \multirow{2}{*}{$\begin{array}{l}\text { Factor } \\
\text { Age (years) }\end{array}$} & & Sedation (SC) $n=1500$ & No Sedation (NSC) $n=194$ & \multirow{2}{*}{ OR [Cl] } & \multirow{2}{*}{$\begin{array}{l}\boldsymbol{P} \text { value } \\
0.283\end{array}$} \\
\hline & & $64(14)$ & $63(15)$ & & \\
\hline Time taken (minutes) & & $29(13)$ & $32(18)$ & - & 0.590 \\
\hline \multirow[t]{3}{*}{ Sex } & Male & $694(46)$ & $119(61)$ & & $<0.001$ \\
\hline & Female & $806(54)$ & $75(39)$ & & \\
\hline & & Number & Number & & \\
\hline \multirow[t]{3}{*}{ Referral } & Routine & 922 & 101 & - & 0.026 \\
\hline & Urgent & 558 & 45 & & \\
\hline & Unknown & 20 & 5 & & \\
\hline \multirow[t]{3}{*}{ Hospital } & A & 539 & 49 & - & $\begin{array}{l}< \\
0.0001\end{array}$ \\
\hline & B & 491 & 33 & & \\
\hline & C & 470 & 18 & & \\
\hline \multirow[t]{5}{*}{ ASA } & 1 & 438 & 14 & - & 0.0003 \\
\hline & 2 & 448 & 29 & & \\
\hline & 3 & 478 & 44 & & \\
\hline & 4 & 113 & 22 & & \\
\hline & Unknown & 23 & 2 & & \\
\hline Therapeutic & & 385 & 21 & $0.8[0.5-1.1]$ & 0.128 \\
\hline Inpatient & & 673 & 43 & $0.9[0.7-1.3]$ & 0.680 \\
\hline Screening & & 31 & 4 & $1.8[0.8-4.1]$ & 0.178 \\
\hline Surveillance & & 161 & 11 & $1.1[0.7-1.7]$ & 0.798 \\
\hline \multirow[t]{3}{*}{ Indication ${ }^{1}$} & Bleeding & 317 & 28 & $1.4[1.0-2.0]$ & 0.034 \\
\hline & Anemia & 125 & 3 & $0.4[0.2-0.8]$ & 0.014 \\
\hline & $\mathrm{CIBH}$ & 297 & 26 & $1.4[1.0-2.0]$ & 0.036 \\
\hline Previous Resection(s) & & 45 & 5 & $1.6[0.8-3.3]$ & 0.225 \\
\hline \multirow[t]{2}{*}{ Pathology 2} & Polyps & 351 & 51 & $1.2[0.9-1.7]$ & 0.249 \\
\hline & Inflammation & 115 & 6 & $0.4[0.2-0.9]$ & 0.025 \\
\hline Done by $2 \mathrm{nd}$ endoscopist & & 217 & 15 & $1.0[0.7-1.6]$ & 0.858 \\
\hline Failed cecal intubation & & 153 & 11 & $1.1[0.7-1.8]$ & 0.624 \\
\hline Adjusted cecal intubation & & 1391 & 185 & $1.6[0.8-3.2]$ & 0.180 \\
\hline \multirow[t]{6}{*}{ Discomfort } & None & 521 & 84 & - & $<0.001$ \\
\hline & Minimal & 529 & 29 & & \\
\hline & Mild & 269 & 13 & & \\
\hline & Moderate & 150 & 9 & & \\
\hline & Severe & 0 & 0 & & \\
\hline & Unrecorded & 31 & 19 & & \\
\hline \multirow[t]{4}{*}{ Complications } & & 30 & 1 & - & 0.351 \\
\hline & Poorly tolerated & 25 & 2 & & \\
\hline & Damaged scope & 3 & 0 & & \\
\hline & Bleeding & 2 & 0 & & \\
\hline
\end{tabular}

Age and time expressed as average (standard deviation). Significant values were $P<0.05$, derived by Chi-square test, t-test or Mann-Whitney. Odds ratio were obtained by univariate analysis.

CIBH: change in bowel habit

${ }^{1}$ Only indications with significant $P$ values are shown

${ }^{2}$ No significant differences were found for diverticular disease, strictures or radiation proctitis.

bility could have affected perception of patient discomfort. However, all units are certified by JAG and follow standard protocol for all procedures for recording discomfort. While endoscopist experience is known to affect polyp detection rates [13,14], it was not controlled for in our study. Because all endoscopists were JAG accredited, it ensured that their skill levels were equal, and therefore, unlikely to influence outcomes.

Multivariate analysis of our results revealed that patients undergoing NSC were more likely to have more comorbidities as evidenced by higher ASA grades. NSC would certainly be a safer option given the risk that sedation poses to cardiovascular stability. We could not determine whether NSC was a patient's or endoscopist's choice, but exploring their motivations might help identify factors that could improve its uptake. We also demonstrated that some hospital units were more likely to use NSC than others, but the decision was not influenced by the endoscopist perform- ing the procedure. Hospital factors that may affect decisions for NSC, such as outcome targets, patient information, informed consent, staff preferences and biases, warrant investigation even though they are likely to vary from one institution to another.

Previous studies have highlighted how discomfort may limit the completion of the procedure, and advocated the benefits of water insufflation [15], sedation on demand (patient controlled), and sedation as needed (endoscopist controlled) [16]. Overall, we showed that NSC can be completed comfortably with minimal variation in technique, supporting previous findings of success more so in men, and that it had no effect on polyp detection rate [3]. Most patients tolerated the procedure well, with either no or minimal discomfort. Successful NSC is less likely with macroscopic inflammation as it was associated with significant discomfort. 
Table 4 Depth of insertion of scope and reasons for failed cecal intubation in NSC patients.

\begin{tabular}{|c|c|c|}
\hline Depth of Insertion & Total & Reason for Failed Intubation (n) \\
\hline Cecum & 115 & \\
\hline Terminal ileum/neo TI & 57 & \\
\hline Anastomosis & 1 & \\
\hline Proximal ascending & 1 & Inadequate bowel prep \\
\hline Hepatic flexure & 2 & Discomfort (1) Bowel redundancy (1) \\
\hline Mid transverse & 3 & $\begin{array}{l}\text { Inadequate bowel prep (2) Discom- } \\
\text { fort (1) }\end{array}$ \\
\hline Splenic flexure & 3 & $\begin{array}{l}\text { Bowel prep (1) Instrument } \\
\text { inadequacy (2) Excess looping (1) }\end{array}$ \\
\hline Proximal descending & 2 & Inadequate bowel prep (2) \\
\hline Distal sigmoid & 5 & $\begin{array}{l}\text { Discomfort (1) Limited by angula- } \\
\text { tion/fixed sigmoid ( } 3 \text { ) } \\
\text { Inadequate bowel prep (1) }\end{array}$ \\
\hline Rectum & 3 & $\begin{array}{l}\text { Inadequate bowel prep (2) Solid stool } \\
\text { obstructing lumen (1) }\end{array}$ \\
\hline $55 \mathrm{~cm}$ & 1 & Not recorded \\
\hline Total completed & 173 & \\
\hline Intubation rate & $89 \%$ & \\
\hline $\begin{array}{l}\text { Adjusted intubation } \\
\text { rate }\end{array}$ & $95 \%$ & $\begin{array}{l}\text { Allowing for inadequate bowel prep } \\
\text { and instrument inadequacy }\end{array}$ \\
\hline
\end{tabular}

Our cecal intubation rate matched that of previous studies [8] and was similar to that achieved when sedation was used. The adjusted cecal intubation rate was $95.4 \%$, which satisfies the standard set by the NHS Bowel Cancer Screening Programme [11]. In addition, polyp detection rates were comparable with both SC and NSC. That suggests that NSC with optimal bowel preparation and adequate instrumentation may achieve the high technical standards required by the screening program. It may also appeal to patients without an escort who are candidates for same-day discharge. A recent study showed that $56.2 \%$ of 964 patients were willing to undergo NSC, and that fear of procedurerelated pain was inversely related to procedure acceptance [17]. As moderate discomfort was described in only $5 \%$ of cases, our study promotes NSC, or at least sedation on demand, although it critically lacked a post-procedure survey of patients' experience. Overall, our results confirm that NSC is a practical option for motivated patients who are adequately counselled prior to the procedure. It has the potential to avoid sedation-related complications, particularly in patients with multiple comorbidities, to prevent delay in discharge from hospital, and to allow near immediate return to normal activity. Therefore patient factors alone may not prevent its uptake.
Competing interests: None

\section{Acknowledgements}

The authors wish to thank Gemma Coward, Endoscopy Unit Audit Co-ordinator, and the Endoscopy Department at Queen Elizabeth the Queen Mother Hospital, Margate, United Kingdom, for their assistance in data collection.

\section{References}

1 Lee TJW, Blanks RG, Rutter MD et al. Efficacy and safety of colonoscopy in the UK NHS bowel cancer screening programme. Gut 2011; 60: A22

2 Waye JD. Colonoscopy. Surg Clin North Am 1972; 52: 1013-1024

3 Bannert C, Reinhart K, Dunkler D et al. Sedation in screening colonoscopy: impact on quality indicators and complications. Am J Gastroenterol 2012; 107: 1837-48

4 Baudet JS, Aguirre-Jaime A. The sedation increases the acceptance of repeat colonoscopies. Eur J Gastroenterol Hepatol 2012; 24: 775 - 780

$5 \mathrm{Ko} C W$, Riffle S, Michaels L et al. Serious complications within 30 days of screening and surveillance colonoscopy are uncommon. Clin Gastro Hepatol 2010; 8: 166-173

6 Safety and Sedation During Endoscopic Procedures. British Society of Gastroenterology Guidelines 2012

7 Jonas DE, Russell LB, Sandler RS et al. Patient time requirements for screening colonoscopy. Am J Gastroenterol 2007; 102: 2401 - 2410

8 Leung FW. Is there a place for sedationless colonoscopy? J Interv Gatroenterol 2011; 1: 19-22

9 Leung FW, Aljebreen AM. Unsedated colonoscopy: Is it feasible? Saudi J Gastroenterol 2011; 17: 289-292

10 Petrini JL, Egan JV, Hahn WV. Unsedated colonoscopy: patient characteristics and satisfaction in a community-based endoscopy unit. Gastrointest Endosc 2009; 69: 567-572

11 Quality Assurance Guidelines for Colonoscopy. NHS BCSP Publication No. 6022011

12 Hemmasi G, Sohrabi M, Zamani F et al. Prevalence of colorectal adenoma in an average-risk population aged $40-50$ versus $50-60$ years. Eur J Cancer Prev 2015; 24: 386-390

13 Lee TJ, Rees CJ, Blanks RG et al. Colonoscopic factors associated with adenoma detection in a national colorectal cancer screening program. Endoscopy 2014; 46: $203-211$

14 Solís-Muñoz P, Solís-Herruzo JA, Rodríguez-Muñoz S. Experience of the endoscopist increases detection rates of smaller size and higher histological grade polyp. J Gastroenterol Hepatol 2014; 29: 1237-1241

15 Terruzzi V, Paggi S, Amato A et al. Unsedated colonoscopy: A neverending story. World J Gastrointest Endosc 2012; 4: 137-141

16 Leung FW, Aljebreen AM, Brocchi E et al. Sedation-risk-free colonoscopy for minimizing the burden of colorectal cancer screening. World J Gastrointest Endosc 2010; 2: 81-89

17 Paggi S, Radaelli F, Amato $A$ et al. Unsedated colonoscopy: an option for some but not for all. Gastrointest Endosc 2012; 75: 392-398 